\title{
Prognostic Factors Associated with the Efficacy of Hepatic Transarterial Embolization in Patients with Neuroendocrine Tumors
}

\author{
Fatores Prognósticos Associados à Eficácia da Embolização Transarterial Hepática em Pacientes \\ com Tumores Neuroendócrinos \\ Jose Eduardo Nuñez ${ }^{1,2} \mathbb{D}$, Charles Zurstrassen¹, Milton Barros', Deise Uema ${ }^{3}$, Rossana Lopez ${ }^{4}$, Rachel Riechelmann ${ }^{\text {* }}$.
}

\begin{abstract}
Introduction: To evaluate the safety and efficacy of hepatic transarterial embolization (TAE) or transarterial chemoembolization (TACE) in patients with irresectable liver metastases from neuroendocrine tumors (NETs) treated at two Brazilian cancer centers. Methods: Retrospective multicenter analysis of patients (pts) with histological diagnosis of neuroendocrine tumor of any origin with unresectable and measurable hepatic metastases who underwent at least one procedure of TAE or TACE. Endpoints: Hepatic progression free survival (HPFS), overall survival (OS), tumor response and toxicity assessment. Results: Thirty-six pts were evaluated. Primary tumors were as follow: midgut 20 pts, pancreas 7 pts, others 9 pts. Most of patients had grade (G) 1-2 tumors (93.3\%). In patients with functioning NETs, clinically significant symptomatic control was $41.7 \%$. Concerning type of embolization (TAE vs TACE), there were no significant differences in the proportion of patients achieving reduction of at least $50 \%$ of 5 HIAA (45.5\% vs $50 \%$ ) and radiological disease control rate (91.3\% vs $92.3 \%$ ), respectively. In a median follow up of 40.8 months $(m)$, median HPFS was $38.9 \mathrm{~m}$, and mean OS was $98 \mathrm{~m}$ (median not reached). No significant differences were found in HPFS or OS by type of embolization procedure. Pancreatic primary tumor and G3 tumor by WHO classification were associated with significantly shorter HPFS. Tumor G3 was also associated with shorter OS. Adverse events of any grade were: abdominal pain (13.8\%), fever (5.5\%), and 2 pts developed biloma. Conclusion: Our study is the first in our region reporting results of TAE/TACE in patients with irresectable liver metastases from NETs. We observed that pts with pancreatic or G3 NET derive less benefit from these procedures. In pts with G1-2 NETs, both techniques offer similar results.
\end{abstract}

Keywords: Embolization, Therapeutic; Chemoembolization, Therapeutic; Neuroendocrine tumors; Neoplasm metastasis.

1. AC Camargo Cancer Center, Medical Oncology - São Paulo - São Paulo - Brazil

2. Instituto do Câncer do Estado de São Paulo, Medical Oncology - São Paulo - São Paulo - Brazil

3. Dresden International University, Center for Clinical Research and Management Education - Dresden - Saxony - Germany

4. AC Camargo Cancer Center, Centro Internacional de Pesquisa - São Paulo - São Paulo - Brazil

Financial support: none to declare.

Conflicts of interest: The authors declare no conflict of interest relevant to this manuscript.

Correspondence author: Rachel Riechelmann. AC Camargo Cancer Center, Medical Oncology - São Paulo - São Paulo - Brazil

Email: rachel.riechelmann@accamargo.org.br

Received on: December 30, 2018 | Accepted on: July 4, 2019

DOI: $10.5935 / 2526-8732.20190018$ 


\section{RESUMO}

Resumo: Introdução: Avaliar a segurança e eficácia da embolização transarterial hepática (TAE) ou quimioembolização transarterial (TACE) em pacientes com metástases hepáticas de tumores neuroendócrinos (TNEs) irressecáveis tratados em dois centros brasileiros de câncer. Métodos: retrospectiva analítica multicêntrica de pacientes (pts) com diagnóstico histológico de tumor neuroendócrino de qualquer origem com metástases hepáticas irressecáveis e mensuráveis que foram submetidas a pelo menos um procedimento de TAE ou TACE. Parâmetros: Sobrevida livre de progressão hepática (SLPH), sobrevida geral (SG), resposta tumoral e avaliação de toxicidade. Resultados: Trinta e seis pts foram avaliados. Os tumores primários foram os seguintes: 20 pts intestino médio, 7 pts pâncreas, 9 pts outros. A maioria dos pacientes apresentava tumores grau (G) 1-2 (93.3\%). Em pacientes com TNEs funcionais, clinicamente o controle sintomático foi significativo foi $41.7 \%$. Em relação ao tipo de embolização (TAE vs TACE), não houve diferenças significativas na proporção de pacientes que obtiveram redução de pelo menos 50\% do 5HIAA (45.5\% vs $50 \%$ ) e a taxa de controle radiológico da doença ( $91.3 \%$ vs $92.3 \%$ ), respectivamente. Em um acompanhamento médio de 40.8 meses $(\mathrm{m})$, a SLPH intermediário foi de $38.9 m$, e a SG média foi de 98m (média não atingida). Não foram encontradas diferenças significativas na SLPH ou na SG pelo tipo de procedimento de embolização. Tumor primário pancreático e tumor G3, pela classificação da OMS, foram também associados com significativa redução da SLPH. O tumor G3 também foi associado com SG reduzida. Os eventos adversos de qualquer grau foram: dor abdominal (13.8\%), febre (5.5\%) e 2 pts desenvolveram biloma. Conclusão: Nosso estudo é o primeiro em nossa área que relata resultados de TAE/TACE em pacientes com metástases hepáticas irressecáveis de TNEs. Observamos que os pacientes com TNE G3 ou pancreático obtêm menos benefícios destes procedimentos. Em pts com TNEs G1-2, ambas as técnicas oferecem resultados similares.

Descritores: Embolização terapêutica; Quimioembolização terapêutica; Tumores neuroendócrinos; Metástases neoplásicas.

\section{INTRODUCTION}

Neuroendocrine tumors (NETs) are uncommon neoplasms. However, their incidence have been increasing over the past decades, with nowadays 5-7 cases per $100,000 .^{1}$ The development of liver metastases from NETs is a frequent event and represents an important prognostic factor regardless of the primary site. ${ }^{2,3}$ It is also known that in the majority of these patients, hepatic metastases are diffuse and unresectable. ${ }^{4}$ In these cases, selective hepatic transarterial embolization (TAE) or transarterial chemoembolization (TACE) can induce objective response and symptom control, particularly in patients with functioning tumors.

The rationale for treatment with TAE and TACE is based on the fact that liver metastases from NETs are hypervascular and derive most of their blood supply from the hepatic artery, whereas normal hepatocytes feed from the portal vein. TAE can be performed using lipiodol, polyvinyl alcohol (PVA), gel foam powder or bland microspheres. TACE has the same principles, but single-agent chemotherapy (doxorubicin, cisplatin, streptozocin) is added, followed by embolizing agents. ${ }^{5}$ Response rates with both techniques, measured by carcinoid symptomatic control (if present), decreased hormone secretion, or radiographic response, are generally over
50 percent, even in the presence of high hepatic tumor burden. ${ }^{6-12}$

There is no evidence about whether TACE offers superior results when compared with $T A E$, or at least when treating patients with midgut NETs liver metastases, which are mostly chemo-resistant. ${ }^{12}$ Despite many studies demonstrating response rates, survival benefits from these techniques are less clear.,5,13-16 Some short term side effects described include abdominal pain, fever, nausea/vomiting, fatigue and biochemical abnormalities (elevated liver enzymes). ${ }^{17}$

Importantly, given the absence of robust randomized trials demonstrating superiority of one technique over the other, both TAE and TACE are considered reasonable approaches for patients with hepatic-predominant disease not suitable for R0 surgical resection. Because targeted agents are not widely available in Brazil due to lack of reimbursement by the public system, TAE/TACE are often utilized to treat NET patients with liver metastases. However, we are unaware of studies on liver embolization from Brazil. Thus, our study aimed to evaluate the radiographic, biologic, and clinical response, safety of TAE and TACE in patients with NETs presenting with hepatic metastases treated at two Brazilian cancer centers. 


\section{METHODS}

\section{Patients}

We performed a retrospective study in patients presenting with metastatic NETs treated with TAE and/or TACE at AC Camargo Cancer Center and Cancer of Institute of Sao Paulo. The selection of patients was made by convenience sampling from a database of carcinoid syndrome and pancreatic NETs. Eligible patients had histological diagnosis of neuroendocrine tumor of any origin, unresectable and measurable metastatic hepatic disease, and underwent at least one procedure of TAE or TACE. The first procedure of embolization was performed in June 2005. The following clinical data were collected retrospectively from electronic medical records: sex, age at the time of first embolization procedure, cell differentiation, ki67 index, metastatic sites, and treatment outcomes. Hepatic tumor burden was stratified by $<50$ and $>50 \%$ liver volume involvement using simple visual estimate.

The primary endpoints were tumor response and hepatic progression free survival (HPFS), which were calculated from the date of first embolization. Secondary endpoints were overall survival (OS) and toxicity assessment. This study was conducted in accordance with the protocol, Good Clinical Practice guidelines of the International Conference on Harmonization (ICH GCP), applicable local laws and regulatory requirements.

\section{Procedure}

Embolization therapies included TAE and TACE. The choice between TAE and TACE was based on the decision of the referring radiologist and the patient's oncologist. The technique, materials and number of therapy sessions were at the discretion of the treating interventional radiologist. TAE was performed using microspheres (Embospheres, Merit Medical, Utah, USA; Embozene, CeloNova, TX, USA) or polyvinyl alcohol (PVA) in sizes ranging from $<150$ to 500um. TACE was performed using lipiodol and doxorubicin. Technical details have been described previously. ${ }^{15,18}$

\section{Assessment of the Efficacy of Embolization Therapy}

All relevant images were retrieved from radiology picture archiving systems to analyze hepatic tumor burden. Images included magnetic resonance (MRI) and computed tomography (CT) scans of the abdomen. Radiological response rates (any radiological tumor shrinkage) were retrospectively determined according to radiological reports. Images were performed every 1-3 months after the procedure. In functioning tumors, dosage of 24 hours urinary 5-HIAA was collected 1-3 months before and after the embolization procedure.

\section{Statistical Analyses}

Baseline characteristics were compared between TAE e TACE groups using Chi-square test and Fisher's exact test for discrete variables, ANOVA methods for continuous variables, and Wilcoxon and Kruskal-Wallis methods for non-normal continuous variables. Survival curves were calculated by the Kaplan-Meier method. HPFS was defined as the time from the start of TAE or TACE until the date of progression, based on radiological reports, in liver or death. OS was defined as the time from the start of TAE or TACE until the date of death or last follow-up. All analyses were performed using the SPSS software, version 22 (IBM Corporation, Armonk, NY, USA).

\section{RESULTS}

\section{Patients}

From June 2005 to January 2018, we included 36 patients. Their baseline characteristics are summarized in Table 1 . The median age was 59 years (range, 19-80), and the proportion of male/female patients was 1 . The primary site of the tumor was midgut in 20 patients (55.6\%), pancreas in 7 patients $(19.4 \%)$, lung in 3 patients (8.3\%), and unknown in 6 patients (16.7\%). The majority of patients (93.3\%) had grade 1-2 tumors. The baseline characteristics were balanced between the patients receiving TAE or TACE.

\section{Outcomes}

In a median follow up of 40.8 months, the median HPFS was 38.9 months, and the mean OS was 98 months $(95 \%$ Cl 73 - 123 months; median not

reached). The disease control rate (complete response + partial response + stable disease) was $92.3 \%$ (12/13 patients) in the case of TACE and $91.3 \%$ (21/23 patients) in the group undergoing TAE. In patients with functioning tumors, clinically significant symptomatic control was seen in 62.5\% (10/16 patients) in the TAE group and $50 \%$ (4/8 patients) in the case of TACE. There was no significant difference in the proportion of patients achieving reduction of at least $50 \%$ of 5 HIAA in relation to type of embolization: TAE vs TACE (5/11 patients, $45.5 \%$ vs $3 / 6$ patients, 50\%; respectively). The median number of embolization procedures was 1 (range 1-5). Fifteen patients underwent more than one embolization procedures.

No significant differences were found in HPFS by type of embolization procedure: TAE vs TACE (nonreached vs. 37 months, $p=0.34$ ); or by number of 
Table 1. Patient characteristics $(\mathrm{N}=36)$.

\begin{tabular}{|c|c|c|c|c|}
\hline \multirow{2}{*}{ Variable } & \multicolumn{3}{|c|}{ No. Patients (\%) } & \multirow{2}{*}{$p$ value } \\
\hline & Total & TAE & TACE & \\
\hline \multicolumn{5}{|l|}{ Gender } \\
\hline Female & $18(50)$ & $12(52.2)$ & $6(46.2)$ & \multirow[t]{2}{*}{0.72} \\
\hline Male & $18(50)$ & $11(47.8)$ & $7(53.8)$ & \\
\hline \multicolumn{5}{|l|}{ Age, y } \\
\hline \multirow[t]{2}{*}{ Median (range) } & 62 & 63 & 59 & \multirow[t]{2}{*}{0.97} \\
\hline & $(19-80)$ & $(19-80)$ & $(41-76)$ & \\
\hline \multicolumn{5}{|l|}{ Primary tumor } \\
\hline Midgut & $20(55.6)$ & $13(56.5)$ & $7(53.8)$ & \multirow[t]{4}{*}{0.52} \\
\hline Pancreas & $7(19.4)$ & $3(13)$ & $4(30.8)$ & \\
\hline Lung & $3(8.3)$ & $2(8.7)$ & $1(7.7)$ & \\
\hline Unknown & $6(16.7)$ & $5(21.7)$ & $1(7.7)$ & \\
\hline \multicolumn{5}{|c|}{ Histological Grade } \\
\hline 1 & $15(50)$ & $11(52.4)$ & $4(44.4)$ & \multirow{3}{*}{0.14} \\
\hline 2 & $13(43.3)$ & $10(47.6)$ & $3(33.3)$ & \\
\hline 3 & $2(6.7)$ & 0 & $2(22.2)$ & \\
\hline \multicolumn{5}{|c|}{ Hepatic Tumor Burden } \\
\hline$<50 \%$ & $18(51.4)$ & $11(47.8)$ & $7(58.3)$ & \multirow[t]{2}{*}{0.55} \\
\hline$\geq 50 \%$ & $17(48.6)$ & $12(52.2)$ & $5(41.7)$ & \\
\hline \multicolumn{5}{|l|}{ Bone Metastases } \\
\hline Yes & $10(27.8)$ & $6(26.1)$ & $4(30.8)$ & \multirow[t]{2}{*}{0.76} \\
\hline No & $26(72.2)$ & $17(73.9)$ & $9(69.2)$ & \\
\hline
\end{tabular}

*Abbreviations: TAE, transarterial embolization; TACE, transarterial chemoembolization.

embolizations: 1 vs more than one (37 vs 38 months, $p=0.98)$; or by hepatic tumor burden $(p=0.93)$. Pancreatic primary was associated with significantly shorter HPFS $(p<0.001)$, as in showed in Figure 1. Additionally, tumor grade 3 was associated with shorter HPFS $(p=0.02)$, as shown in Figure 2.

In terms of OS, no significant differences were found by type of embolization procedure: TAE vS TACE (42 months vs. not-reached, $p=0.29$ ), or by number of embolizations: 1 vs more than one (42 months vs not-reached, $p=0.15)$; or by hepatic tumor burden $(p=0.19)$. Pancreatic primary showed a tendency of shorter OS $(p=0.07)$, as shown in Figure 3. Grade 3 NET was associated with shorter OS $(p=0.01)$, showed in Figure 4. The presence of bone metastases did not significantly impact OS ( $p=0.97)$.

\section{Adverse Events}

The most frequent adverse event of any grade was abdominal pain after the procedure in $13.8 \%(5 / 36)$ of patients. Fever was reported in $5.5 \%(2 / 36)$, and 2 patients developed biloma (one with TACE and one with TAE). There were no cases of procedure-related deaths.

\section{DISCUSSION}

This study shows improved clinical outcomes following TAE or TACE with significant symptomatic control and radiologic response. Our experience compares similarly with those of previously reported series from around the world. As we know, there have been no randomized controlled trials to confirm the survival benefit of TAE or TACE, and the positioning of these therapies in the treatment sequencing of NETs is not well defined in guidelines. ${ }^{19,20}$ Nevertheless, liver embolization is an effective treatment for hepatic-predominant metastatic well-differentiated NETs.

In numerous studies of embolization therapy, patients with functioning NETs presenting with liver metastases showed up to $75 \%$ of symptomatic improvement in flushing and diarrhea.9,21-23 Objective radiological response rates have ranged from 11 to 100 percent. $^{5}$ Our study reported a lower rate of symptomatic control. This is probably due to differences among populations, more advanced disease or concomitant systemic therapies received by patients in those studies during the embolization procedures. However, in our overall population (functioning and non-functioning tumors), we saw a marked rate of radiologic response, which is concordant with other series as mentioned above. 


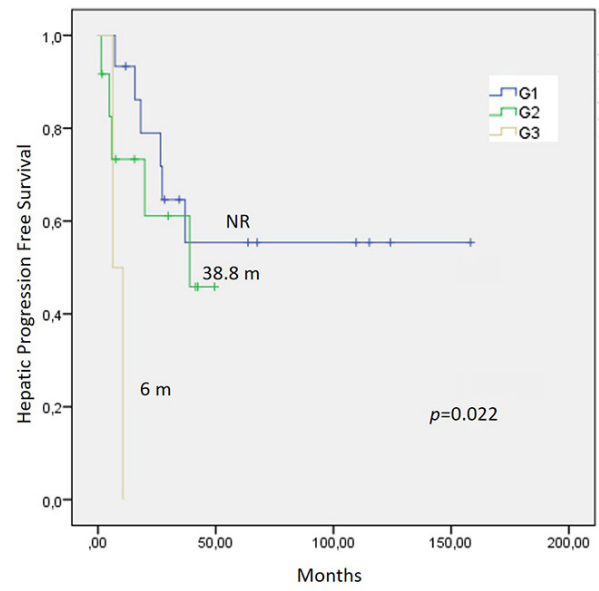

Figure 1. Hepatic Progression Free Survival after embolization procedure (TAE or TACE) in relation to tumor grade. Abbreviations: HPFS, Hepatic Progression Free Survival; TAE, transarterial embolization; TACE, transarterial chemoembolization; NR, not reached.

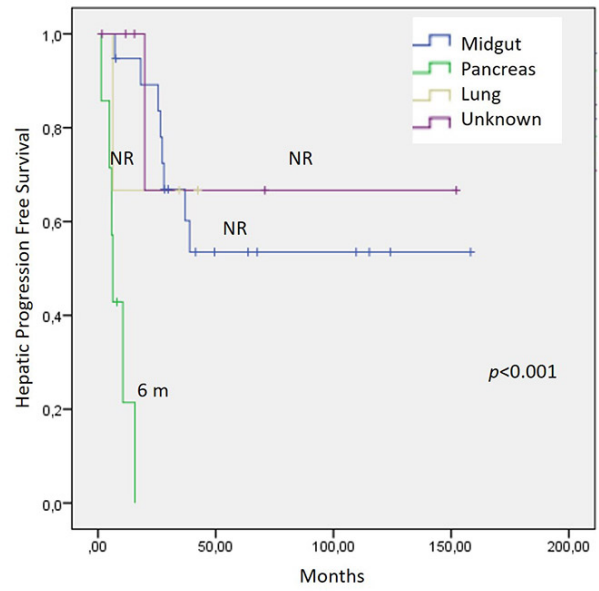

Figure 2. Hepatic Progression Free Survival after embolization procedure (TAE or TACE) in relation to primary site. Abbreviations: HPFS, Hepatic Progression Free Survival; TAE, transarterial embolization; TACE, transarterial chemoembolization; NR, not reached.

The reported median progression free survival and median overall survival from previous embolization studies ranged between 16 to 23 months and 18 to 80 months, respectively..$^{5,12}$ In the whole population of our study, HPFS and OS were superior to previous reports. These differences could be attributed to characteristics of patients or systemic treatment in studies, including ours. Importantly, this presents the question of the best time to perform embolization procedures: sequential or concomitant

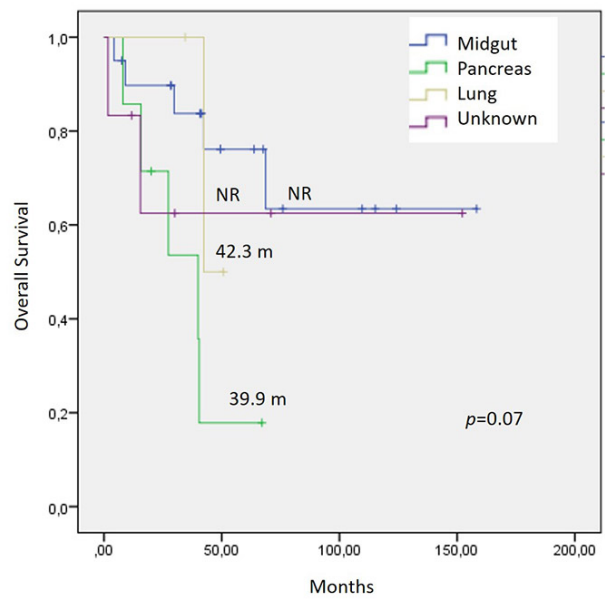

Figure 3. Overall Survival after embolization procedure (TAE or TACE) in relation to primary site.Abbreviations: OS, Overall Survival; TAE, transarterial embolization; TACE, transarterial chemoembolization; NR, not reached.

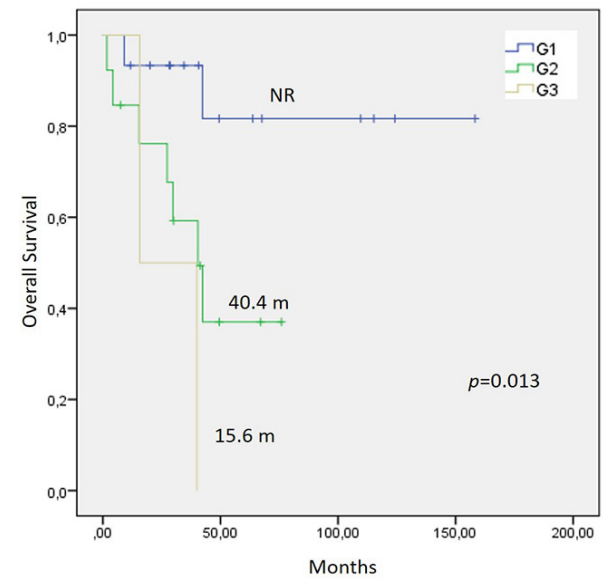

Figure 4. Overall Survival after embolization procedure (TAE or TACE) in relation to tumor grade. Abbreviations: OS, Overall Survival; TAE, transarterial embolization; TACE, transarterial chemoembolization; NR, not reached.

with other therapies, at progression or for tumor burden control. What is clear, however, is that a multidisciplinary approach to the treatment of NET patients with liver metastasis improves survival opportunities.

In our study, higher histological grade derived in shorter HPFS and OS, in concordance with other series. ${ }^{24}$ Hepatic tumor burden of more than $50 \%$ has been correlated with poorer survival. ${ }^{25}$ Nevertheless, it was not corroborated in our study likely because if our small (and underpowered) sample. The presence of extrahepatic disease is not a contraindication to TAE or TACE for metastatic NETs, 
especially for highly symptomatic functioning NET patients. $8,15,24$

Previous studies have reported conflicting survival outcomes for pancreatic NETs versus NETs from other origin. ${ }^{12,14,24-26}$ In one of the largest series, the addition of chemotherapy to embolization seemed to benefit patients with pancreatic NETs but not with carcinoid tumors. ${ }^{12}$ Our study found no significant OS difference between primary tumors. However, there was a significant difference in HPFS, with a lower survival for pancreatic tumors, which probably reflects the worse prognosis of pancreatic NETs regardless of the technique.

Survival outcomes by type of embolization modality (TAE or TACE) in this study were within range of other series. ${ }^{24,27,28}$ In addition, the absence of difference in OS and HPFS between TACE and TAE in our study are also supported in the literature. ${ }^{14,24,25,29}$ A comparison of the effectiveness in midgut or pancreatic NETs from one or another technique was not possible due to our small sample size.

Adverse events were mild in our population, which is concordant with reported morbidity of TAE and TACE. ${ }^{17}$ One study raised concern about a high incidence of biliary injury with transarterial chemoembolization (TACE) using drug-eluting beads, ${ }^{30}$ however it was not reported in other studies. ${ }^{31,32}$ In our study, less frequent incidence of biliary injury were observed, and it was similar with either TAE or TACE.

In the context of metastatic NETs, randomized phase 3 trials with systemic therapies showed improvement in PFS versus placebo, in the case of somatostatin analogues, PROMID (14.3 months) and CLARINET (median PFS not reached); and with everolimus, RADIANT 3 (11 months). Our study demonstrates that embolization therapy with a median PFS of 27.2 months is effective and safe, and is an excellent option for patients with functioning tumors particularly in the public system of developing countries like ours, where long-acting presentations of somatostatin analogues (SSA) are often not available. In these cases, a recommendation is to hospitalize the patient, initiate treatment with short-acting SSA, and control the symptoms with TAE or TACE, in order to avoid carcinoid crisis. ${ }^{33}$

In terms of new loco-regional therapies, radioembolization with $90-Y$ in metastatic NETs is a new technique with limited but growing use. Similarly to other techniques, it has been reported to reduce symptoms in approximately $50 \%$ of patients with functioning tumors. ${ }^{34}$ However, this is not widely available in Brazil.

Our study has the inherent limitations of its retrospective design, as well as a small cohort size. Prospective studies are still awaited and should clarify the optimal indication of TAE or TACE. However, our study is the first in our region reporting results of these hepatic artery embolization techniques, showing that TAE and TACE are effective and feasible treatment options in NET patients with unresectable liver metastasis.

In conclusion, we believe that TAE and TACE are effective to treat liver metastases from well- differentiated NETs. Both techniques have apparently similar effica$\mathrm{cy}$, and therefore we prefer to perform TAE ${ }^{35}$ because it is cheaper and less toxic. Embolization procedures can be repeated if good hepatic function is present. Importantly, our results reinforce the fact that these procedures are not good options for G3 tumors.

\section{Disclosure}

The authors have stated that they have no conflicts of interest.

\section{AUTHOR'S CONTRIBUTION}

Jose Eduardo Nuñez: Collection and assembly of data, Conception and design, Data analysis and interpretation, Final approval of manuscript, Manuscript writing, Provision of study materials or patient.

Charles Zurstrassen: Collection and assembly of data, Data analysis and interpretation, Final approval of manuscript, Manuscript writing, Provision of study materials or patient.

Milton Barros: Collection and assembly of data, Data analysis and interpretation, Final approval of manuscript, Manuscript writing, Provision of study materials or patient.

Deise Uema: Collection and assembly of data, Data analysis and interpretation, Final approval of manuscript, Manuscript writing, Provision of study materials or patient.

Rossana Lopez: Collection and assembly of data, Data analysis and interpretation, Final approval of manuscript, Manuscript writing, Provision of study materials or patient.

Rachel Riechelmann: Collection and assembly of data, Conception and design, Data analysis and interpretation, Final approval of manuscript, Manuscript writing, Provision of study materials or patient. 


\section{REFERENCES}

1. Yao JC, Hassan M, Phan A, Dagohoy C, Leary C, Mares JE, et al. One hundred years after "carcinoid": Epidemiology of and prognostic factors for neuroendocrine tumors in 35,825 cases in the United States. J Clin Oncol. 2008 Jun;26(18):3063-72.

2. Rindi G, D’Adda T, Froio E, Fellegara G, Bordi C. Prognostic factors in gastrointestinal endocrine tumors. Endocr Pathol. 2007 Feb;18(3):145-9.

3. Dasari A, Shen C, Halperin D, Zhao B, Zhou S, Xu $Y$, et al. Trends in the incidence, prevalence, and survival outcomes in patients with neuroendocrine tumors in the United States. JAMA Oncol. 2017 Oct;3(10):1335-42.

4. Pape UF, Berndt U, Müller-Nordhorn J, Böhmig $M$, Roll S, Koch $M$, et al. Prognostic factors of long-term outcome in gastroenteropancreatic neuroendocrine tumours. Endocr Relat Cancer. 2008 Dec;15(4):1083-97.

5. Kennedy A, Bester L, Salem R, Sharma RA, Parks RW, Ruszniewski P. Role of hepatic intra-arterial therapies in metastatic neuroendocrine tumours (NET): guidelines from the net-liver-metastases consensus conference. HPB (Oxford). 2015 Jan; 17(1):29-37.

6. Ruszniewski $\mathbf{P}$, Rougier $\mathrm{P}$, Roche $\mathrm{A}$, Legmann $\mathrm{P}$, Sibert A, Hochlaf S, et al. Hepatic arterial chemoembolization in patients with liver metastases of endocrine tumors a prospective phase II study in 24 patients. Cancer. 1993 Apr;71(8):2624-30.

7. King J, Quinn R, Glenn DM, Janssen J, Tong D, Liaw $W$, et al. Radioembolization with selective internal radiation microspheres for neuroendocrine liver metastases. Cancer. 2008 Sep;113(5):921-9.

8. Arrese D, McNally ME, Chokshi R, Feria-Arias E, Schmidt C, Klemanski D, et al.

9. Extrahepatic disease should not preclude transarterial chemoembolization for metastatic neuroendocrine carcinoma. Annals of Surgical Oncology. 2013 Mar;20(4):1114-20.Gupta S, Yao JC, Ahrar K, Wallace MJ, Morello FA, Madoff DC, et al. Hepatic artery embolization and chemoembolization for treatment of patients with metastatic carcinoid tumors: The M.D. Anderson experience. Cancer J. 2003 Jul/Aug;9(4):261-7.

10. Swärd C, Johanson V, Nieveen Van Dijkum E, Jansson S, Nilsson O, Wängberg B, et al.

11. Prolonged survival after hepatic artery embolization in patients with midgut carcinoid syndrome. Br J Surg. 2009 May;96(5):517-21. Drougas JG, Anthony LB, Blair TK, Lopez RR, Wright JK, Chapman WC, et al. Hepatic artery chemoembolization for management of patients with advanced metastatic carcinoid tumors. Am J Surg. 1998 May;175(5):408-12.
12. Gupta S, Johnson MM, Murthy R, Ahrar K, Wallace MJ, Madoff DC, et al. Hepatic arterial embolization and chemoembolization for the treatment of patients with metastatic neuroendocrine tumors: variables affecting response rates and survival. Cancer. 2005 Oct;104(8):1590-602.

13. Dong X Da, Carr BI. Hepatic artery chemoembolization for the treatment of liver metastases from neuroendocrine tumors: a long-term follow-up in 123 patients. Med Oncol. 2011 Dec;28(Suppl 1):\$286-90.

14. Pitt SC, Knuth J, Keily JM, McDermott JC, Weber $\mathrm{SM}$, Chen $\mathrm{H}$, et al. Hepatic neuroendocrine metastases: chemo- or bland embolization?. J Gastrointest Surg. 2008 Nov;12(11):1951-60.

15. Ruutiainen AT, Soulen MC, Tuite CM, Clark TWI, Mondschein JI, Stavropoulos SW, et al. Chemoembolization and bland embolization of neuroendocrine tumor metastases to the liver. J Vasc Interv Radiol. 2007 Jul;18(7):847-55.

16. Schell SR, Camp ER, Caridi JG, Hawkins IF. Hepatic artery embolization for control of symptoms, octreotide requirements, and tumor progression in metastatic carcinoid tumors. J Gastrointest Surg. 2002 Sep/Oct;6(5):664-70.

17. Lewis MA, Jaramillo S, Roberts L, Fleming CJ, Rubin J, Grothey A. Hepatic artery embolization for neuroendocrine tumors: postprocedural management and complications. Oncologist. 2012;17(5):725-31.

18. de Baere T, Arai Y, Lencioni R, Geschwind JF, Rilling $W$, Salem R, et al. Treatment of liver tumors with lipiodol TACE: technical recommendations from experts opinion. Cardiovasc Intervent Radiol. 2016 Mar;39(3):334-43.

19. Pavel M, O'Toole D, Costa F, Capdevila J, Gross $D$, Kianmanesh $R$, et al. ENETS consensus guidelines update for the management of distant metastatic disease of intestinal, pancreatic, bronchial neuroendocrine neoplasms (NEN) and NEN of unknown primary site. Neuroendocrinology. 2016;103(2):172-85.

20. Harbert GM, Brame RG, McGaughey HS, Thornton WN. Fetomaternal water exchange. Obstet Gynecol. 1968 Oct;32(2):232-40.

21. Ruszniewski P, Malka D. Hepatic arterial chemoembolization in the management of advanced digestive endocrine tumors. Digestion. 2000;62(Suppl 1):79-83.

22. Strosberg JR, Choi J, Cantor AB, Kvols LK. Selective hepatic artery embolization for treatment of patients with metastatic carcinoid and pancreatic endocrine tumors. Cancer Control. 2006 Jan;13(1):72-8. 
23. Eriksson BK, Larsson EG, Skogseid BM, Löfberg AM, Lörelius LE, Öberg KE. Liver embolizations of patients with malignant neuroendocrine gastrointestinal tumors. Cancer. 1998 Dec;83(11):2293-301.

24. Pericleous M, Caplin ME, Tsochatzis E, Yu D, Morgan-Rowe L, Toumpanakis C. Hepatic artery embolization in advanced neuroendocrine tumors: efficacy and long-term outcomes. Asia Pac J Clin Oncol. 2016 Mar;12(1):61-9.

25. Sofocleous CT, Petre EN, Gonen M, Reidy-Lagunes D, Ip IK, Alago W, et al. Factors affecting periprocedural morbidity and mortality and long-term patient survival after arterial embolization of hepatic neuroendocrine metastases. J Vasc Interv Radiol. 2014 Jan;25(1):22-30.

26. Ho AS, Picus J, Darcy MD, Tan B, Gould JE, Pilgram TK, et al. Long-term outcome after chemoembolization and embolization of hepatic metastatic lesions from neuroendocrine tumors. AJR Am J Roentgenol. 2007 May;188(5):1201-7.

27. Kulke $M H$, Shah $M H$, Benson $A B$, Bergsland $E$, Berlin JD, Blaszkowsky LS, et al. Neuroendocrine tumors, version 1.2015. J Natl Compr Cancer Netw. 2015 Jan;13(1):78-108.

28. Gaba RC. Chemoembolization practice patterns and technical methods among interventional radiologists: results of an online survey. AJR Am J Roentgenol. 2012 Mar;198(3):692-9.
29. Fiore F, Del Prete M, Franco R, Marotta V, Ramundo $V$, Marciello $F$, et al. Transarterial embolization (TAE) is equally effective and slightly safer than transarterial chemoembolization (TACE) to manage liver metastases in neuroendocrine tumors. Endocrine. 2014 Sep;47(1):177-82.

30. Bhagat N, Reyes DK, Lin M, Kamel I, Pawlik TM, Frangakis $C$, et al. Phase II study of chemoembolization with drug-eluting beads in patients with hepatic neuroendocrine metastases: high incidence of biliary injury. Cardiovasc Intervent Radiol. 2013;36(2):449-59.

31. de Baere T, Deschamps F, Teriitheau C, Rao P, Conengrapht K, Schlumberger M, et al. Transarterial chemoembolization of liver metastases from well differentiated gastroenteropancreatic endocrine tumors with doxorubicin-eluting beads: preliminary results. J Vasc Interv Radiol. 2008 Jun;19(6):855-61.

32. Gaur SK, Friese JL, Sadow CA, Ayyagari R, Binkert CA, Schenker MP, et al. Hepatic arterial chemoembolization using drug-eluting beads in gastrointestinal neuroendocrine tumor metastatic to the liver. Cardiovasc Intervent Radiol. 2011 Jun;34(3):566-72.

33. MotaJM, Sousa LG, Riechelmann RP. Complications from carcinoid syndrome: review of the current evidence. Ecancermedicalscience. 2016 Aug; 10:662.

34. Cao CQ, Yan TD, Bester L, Liauw W, Morris DL. Radioembolization with yttrium microspheres for neuroendocrine tumour liver metastases. $\mathrm{Br}$ J Surg. 2010 Apr;97(4):537-43. 